\title{
DISSOCIATION OF SINGLE-STRANDED DNA FROM NUCLEOSOMES FOLLOWING MODIFICATION WITH ACETIC ANHYDRIDE
}

\author{
Juan Jordano*, Francisco Montero**, and Enrique Palacián* \\ *Centro de Biología Molecular. \\ Consejo Superior de Investigaciones Cientificas \\ and Universidad Autónoma de Madrid, \\ Canto Blanco, Madrid-34, Spain \\ * Departamento de Bioquímica, \\ Facultad de Ciencias Químicas, \\ Universidad Complutense, Madrid-3, Spain
}

SUMmaRY Modification with acetic anhydride of nucleosomes from chicken erythrocytes at low ionic strength (less than $0.1 \mathrm{M}$ NaCl) is accompanied by the formation of residual particles and the release of free DNA. This DNA has been identified as singlestranded by thermal denaturation, digestion with nuclease s1, and elution from hydroxyapatite. In contrast, if modification takes place at $0.6 \mathrm{M} \mathrm{NaCl}$, the liberated DNA is mainly doublestranded. The release of the free energy stored in folded nucleosomal DNA, triggered by the weakening of lysine-DNA interactions which takes place upon modification, might be responsible for the observed denaturation of DNA at low ionic stregth.

It is well known that the decrease in the electrostatic interactions of the nucleosomal core by exposure to high ionic strength, $2 \mathrm{M} \mathrm{NaCl}$, is accompanied by dissociation into doublestranded DNA and the histone octamer $(1,2)$. Al low ionic strength, less than $0.1 \mathrm{M} \mathrm{NaCl}$, modification of the lysine residues of histones with carboxylic acid anhydrides produces the disassembly of nucleosomes, with the release of free DNA and the formation of residual DNA-histone particles $(3,4)$. The purpose of the present work is the characterization of the free DNA $1 \mathrm{ib-}$ erated from nucleosomes following modification with acetic anhydride.

\section{MATERIALS AND MBTHODS}

Preparation of nucleosomal particles and double-stranded DNA. Nuclei were obtained from chicken erythrocytes after lysis of the cells in a buffer solution containing 0.58 Nonidet $P 40$ (5). 
Mononucleosomes were prepared by digestion of the isolated nuclei with micrococcal nuclease (Worthington), and fractionation of the digestion products by centrifugation on a 5-208 linear sucrose gradient (6). Nucleosomal DNA had an average length of $160 \pm 10$ base pairs as compared with the digestion products of plasmid pBR 322 treated with nuclease Hae III. Double-stranded DNA used as a control was obtained from mononucleosomes by digesting the particles with pancreatic RNase and proteinase $k$, followed by extraction of the digested proteins with chloroform/ isoamyl alcohol $(24 / 1, v / v)$, and precipitation of DNA with 2 volumes of cold ethanol (7). The concentration of nucleosomal particles was determined spectrophotometrically, taking $A_{260}=20.0$ for a solution containing $1.0 \mathrm{mg} \mathrm{DNA} / \mathrm{ml}$.

Treatment of nucleosomal particles and double-stranded DNA with acetic anhydride. Nucleosomes $(0.2 \mathrm{mg}$ DNA $/ \mathrm{ml})$ or free doublestranded DNA obtained from them $(0.2 \mathrm{mg} / \mathrm{ml})$, in $10 \mathrm{mM} 4-\left(2-\right.$ hy $^{-}$ droxyethyl)-1-piperazineethanesulfonic acid $\left(\mathrm{K}^{+}\right)(\mathrm{pH} 8.2), 5 \mathrm{mM}$ EDTA and $0.1 \mathrm{mM}$ phenylmethylsulfonyl fluoride (low ionic strength), were treated with acetic anhydride $(1.5 \mathrm{mg} / \mathrm{ml})$ at room temperature with continuous gentle stirring. The pi was maintained at 8.2 by addition of $0.5 \mathrm{M} \mathrm{KOH}$ with a Radiometer titration assembly (Copenhagen). After $1 \mathrm{~h}$ of treatment, no base had to be added to maintain stable the $\mathrm{pH}$, indicating that the reagent had been consumed. Nucleosomal particles were also treated in the presence of $0.6 \mathrm{M} \mathrm{NaCl}$ (high ionic strength), other conditions being unchanged. The hydrolyzed reagent was eliminated by overnight dialysis at $2-4^{\circ} \mathrm{C}$ against $10 \mathrm{mM}$ Tris-HCI (pH 8.2), $5 \mathrm{mM}$ EDTA and $0.1 \mathrm{mM}$ phenylmethylsulfonyl fluoride. For the preparation treated at high ionic strength, the dialysis buffer also contained $0.6 \mathrm{M} \mathrm{NaCl}$.

Sedimentation analysis and fractionation. The nucleosomal preparations $(0.2 \mathrm{mg}$ DNA) were centrifuged in linear 5-208 sucrose gradients containing $10 \mathrm{mM}$ Tris-HCl (pH 8.2), $5 \mathrm{mM}$ EDTA and 0.1 $\mathrm{mM}$ phenylmethylsulfonyl fluoride. For the preparation modified at high ionic strength and the corresponding control the gradients also included $0.6 \mathrm{M} \mathrm{NaCl}$. Centrifugation was conducted in a Beckman SW40 rotor at $30,000 \mathrm{rpm}$ and $6^{\circ} \mathrm{C}$ for $26 \mathrm{~h}$. The distribution along the gradient of material absorbing at $254 \mathrm{~nm}$ was determined with an ISCO density fractionator, which was also used for the separation of fractions.

Thermal denaturation. After dialysis of the samples against 0.25 mM EDTA (pH 8.2), denaturation profiles were obtained with a Beckman DU-8 spectrophotometer equipped with a TM.S module, using a heating rate of $0.5^{\circ} \mathrm{C} / \mathrm{min}$. Absorbance at $260 \mathrm{~nm}$ was registered at $1^{\circ} \mathrm{C}$ intervals between $30^{\circ} \mathrm{C}$ and $102^{\circ} \mathrm{C}$ using a slit of $0.5 \mathrm{~nm}$. Hyperchromicity values and the derivative, $\mathrm{dH} / \mathrm{dt}$, were obtained from the registered data by using an HP-85 minicomputer, as previously described (8).

Digestion with nuclease S1. DNA samples (approximately $10 \mu \mathrm{g}$ ), in $1 \mathrm{mI}$ of $50 \mathrm{mM}$ sodium acetate (pt 4.5$), 0.2 \mathrm{M} \mathrm{NaCl}$ and $4 \mathrm{~mm}$ $\mathrm{ZnSO}_{4}$, were incubated with 500 units of nuclease $\mathrm{S1}$ (Sigma) at $37^{\circ} \mathrm{C}$ for $1 \mathrm{~h}$. The degree of digestion was estimated from the hyperchromicity produced. Absorbance at $260 \mathrm{~nm}$ was measured before and after digestion, and from these values the hyperchromicity was obtained. 


\section{RESULTS AND DISCUSSION}

Modification of nucleosomal particles, at low ionic strength, with the reagent for protein amino groups acetic anhydride is accompanied by changes in sedimentation pattern which are shown in Figure 1A. Two components are observed which have sedimentation coefficients smaller than that of the original particles. As shown in a previous work (3), the fast component (component I) corresponds to residual particles containing part of the DNA and all the core histones present in the original preparation, while the slow component (component II) is formed by free DNA. When a similar treatment with acetic anhydride takes place in the presence of $0.6 \mathrm{M} \mathrm{NaCl}$ (high ionic strength), conditions which cause a weakening of the electrostatic interactions between histones and DNA, all nucleosomal particles are dissociated to produce free DNA. The main component observed in sedimentation (Figure (B) corresponds to released DNA and is practically devoid of histones.

Thermal denaturation profiles of the different DNA-containing fractions obtained by modification with acetic anhydride are shown in Figure 2 . The residual particles produced at low ionic strength (component I) develop approximately the same hyperchromicity on thermal denaturation (31.38) as the corresponding untreated nucleosomes $(32.68)$, indicating that the DNA is present in the residual particles as a double strand. The stabilization of DNA by histones in the residual particles is much smaller than in the untreated nucleosomes (Figure 2A): most of the nucleotide base pairs in the residual particles melt at temperatures lower than those corresponding to the DNA in control nucleosomes. The present results are in agreement with those previously obtained with dimethylmaleic anhydride (4). The DNA released at low ionic strength (component II) produces low hyperchromici- 

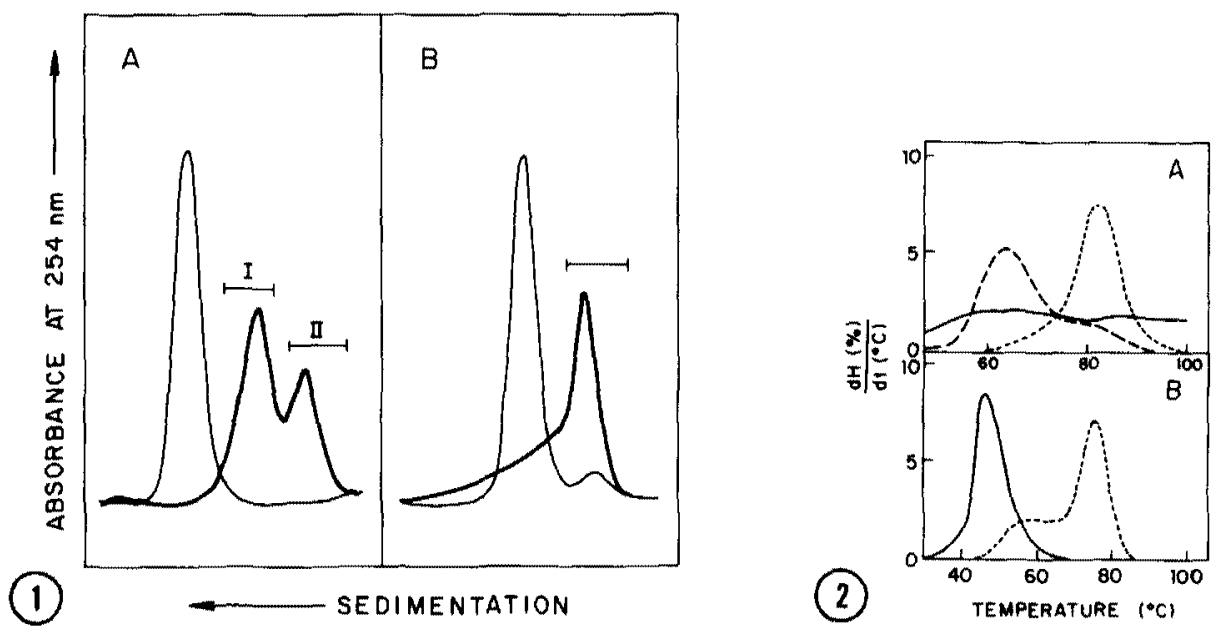

Fig.1. Sedimentation patterns of nucleosomal preparations treated with acetic anhydride at $10 \mathrm{w}(\mathrm{A})$ and $\mathrm{high}(0.6 \mathrm{M} \mathrm{NaCl})(\mathrm{B})$ Ionic strength. The superimposed thin tracings refer to the unmodified control nucleosomes centrifuged under the conditions of the corresponding samples.

Fig. 2. Thermal denaturation profiles of the DMA released from nucleosomes by acetic anhydride at ${ }^{\circ}$ ow and high ionic strength. A) Residual nucleosomal particles (component $I$ in Figure (A) (--) and released DNA (component II in Figure 1A) (-) obtained by modification with acetic anhydride at low ionic strength, and the corresponding control nucleosomes $(\ldots \ldots \ldots)$. B) DNA released by modification at high ionic strength $(0.6 \mathrm{M} \mathrm{NaCl})$ (Figure 1B) (-), and the corresponding control nucleosomes $(\ldots \ldots)$.

ty on thermal denaturation (less than 108), which is consistent with the possibility that most of the DNA be single-stranded. In addition, the thermal denaturation profile (Figure $2 \mathrm{~A}$ ) shows no defined thermal transitions, which indicates the absence of double-stranded DNA. In contrast, most of the DNA released by modification at high ionic strength appears to be double-stranded. This DNA fraction shows a hyperchromicity value comparable to that of the control nucleosomes, and has a clearly-defined thermal transition centered at $46^{\circ} \mathrm{C}$ (Figure 2B), which corresponds to free double-stranded DNA. The difference in denaturation profile of the unmodified controls subjected to low or high ionic strength is probably due to dissociation from nucleosomal particles at $0.6 \mathrm{M} \mathrm{NaCl}$ of histones $\mathrm{H} 1$ and $\mathrm{H} 5$ (9). 
To confirm the single- and double-stranded nature of the DNA liberated at low and high ionic strength, respectively, the two DNA fractions were subjected to treatment with nuclease $\mathrm{S} 1$, an enzyme that degrades specifically single-stranded DNA (10). Table I shows that the DNA released at low ionic strength is completely digested by nuclease S1, with an increase in absorbance at $260 \mathrm{~nm}$ very close to that obtained with thermally denatured nucleosomal DNA. On the other hand, the DNA released at high ionic strength is only partially digested by the enzyme, giving a low hyperchromicity value consistent with only approximately one third of the DNA being single-stranded. When free double-stranded DNA, obtained from the mononucleosomes preparation used for the described experiments, is treated with acetic anhydride under the conditions used for the modification of nucleosomes at low ionic strength, no change detectable with nuclease $\mathrm{S} 1$ is observed, thus excluding a direct effect on DNA of the reagent treatment as the cause of single-stranded DNA production. The single-stranded nature of the DNA released from nucleosomes at low ionic strength is also supported by the elution from hydroxyapatite (11). Less than 108 of this DNA is bound to hydroxyapatite at $150 \mathrm{mM}$ sodium phosphate buffer (pH 6.9), a value close to that obtained for thermally denatured nucleosomal DNA, while $50 \%$ of the DNA released at high ionic strength and 908 of the control double-stranded nucleosomal DNA are bound under these conditions. In all cases, complete recovery of the bound DNA was obtained by elution with $500 \mathrm{~mm}$ sodium phosphate buffer ( $\mathrm{pH} 6.9)$.

Once the single-stranded nature of the DNA released at low ionic strength was confirmed, we tried to exclude any possible artifacts that could account for its production. Although modification took place under carefully controlled conditions to 
prevent any significant change in $\mathrm{pH}$ (see Materials and Methods), and free nucleosomal DNA remains double-stranded after the same treatment used to modify nucleosomes (Table I), a control was made to exclude the changes in $\mathrm{pH}$ during modification as the cause of single-stranded DNA production. The control consisted in treating nucleosomes, under the modification conditions, with an amount of acetic acid equivalent to that of acetic anhydride used for modification. In this control, the pH changes detected with the pH-meter were larger than those taking place during modification, since the liberation of protons from the anhydride is gradual while the diffusion from the acid aliquots added is sudden. Sedimentation analysis of this control shows that less than $10 \%$ of free DNA is released. This DNA as well as the DNA extracted from the nucleosomal particles is double-stranded. In contrast, in the preparation treated with the equivalent amount of acetic anhydride, 508 of the total DNA is liberated as single-stranded DNA. In DNA, acetic anhydride is known to react with only the free $3^{\prime-O H}$ of deoxyribose in the $3^{\prime}$-terminal nucleotide residue (12). However, to exclude an ex-

\section{TABLE I}

Digestion by nuclease $\mathrm{S} 1$ of the DNA released from nucleosomal particles by acetic anhydride at low and high ionic strength

\begin{tabular}{lc}
\hline DNA preparation & $\begin{array}{c}\text { Hyperchromicitya } \\
(8)\end{array}$ \\
\hline Control DNA (double-stranded)a & 0 \\
Control DNA, after heatingb & 32.1 \\
Acetic anhydride-treated DNA & 1.5 \\
Acetic anhydride-treated DNA, after heating & 32.1 \\
DNA released at low salt & 31.6 \\
DNA released at high salt (0.6 M Nacl) & 13.1 \\
DNA released at high salt, after heatingb & 32.3 \\
\hline
\end{tabular}

In all cases, the hyperchromicity obtained with control doublestranded DNA (13.58) was substracted.

benatured by boiling for $5 \mathrm{~min}$. 
tensive modification of DNA as the cause of DNA dissociation and denaturation, the extent of DNA modification with acetic anhydride was determined. Approximately 0.5 acetyl residues were incorporated for each 160 nucleotide-chain, as determined by measuring the radioactivity from $(1-14 \mathrm{C})$ acetic anhydride incorporated into DNA. No difference in the degree of modification was found between the DNA present in the residual particles and the released DNA.

As shown in this work, the weakening of histone-DNA interactions at low ionic strength by modification of lysine residues with acetic anhydride is accompanied by aissociation from nucleosomes of single-stranded DNA. In contrast, at $0.6 \mathrm{M} \mathrm{NaCl}$, at least 508 of the DNA released is double-stranded. Under these higher salt conditions, shielding of the electrostatic repulsions between the negatively-charged DNA strands is increased. Therefore, a larger amount of energy should be required to denature DNA, which might account for the release of double-stranded DNA at high salt. Apparently, the energy stored in nucleosomal DNA, in its superhelical coiling around the histone octamer, could be used to separate the two DNA strands at low ionic strength. Alternative explanations must account for the energy needed to denature DNA, and for the requirement of the nucleosomal structure to produce this phenomenon under our experimental conditions.

DNA replication and RNA transcription are both dependent on the separation of the two strands of double-helix DNA. It has been shown that nucleosomes are present in the regions of the eukaryotic genome where replication and transcription are taking place (13). Different models of nucleosome behaviour in replication and transcription have been proposed which implicate complexes of single-stranded DNA with core histones $(14,15)$. The 
release of single-stranded DNA reported in this paper might explain the formation of the proposed complexes involving singlestranded DNA. The structural peculiarities found in active chromatin, such as chemical modification and association with certain nonhistone proteins $(1,2)$, would be required for the weakening of histone-DNA interactions needed to induce separation of the DNA strands during transcription.

Acknowledgements. We thank Dr. Juan Modolell and Dr. Margarita Salas for critical reading of the manuscript, and Dr. Jesús Avila for helpful suggestions. This work was supported in part by the Fondo de Investigaciones Sanitarias and Comisión Asesora de Investigación científica y Técnica (Spain).

\section{RBFBRBNCES}

1. McGhee, J.D., and Felsenfeld, G. (1980) Ann. Rev. Biochem. $49,1115-1156$.

2. Sperling, R., and Wachtel, E.J. (1981) Adv. Prot. Chem. 34, $1-60$.

3. Jordano, J., Montero, F., and Palacián, E. (1984) Biochemistry (in press).

4. Jordano, J., Montero, F., and Palacián, E. (1984) Biochemistry (in press).

5. Weintraub, H., Palter, K., and Van Lente, F. (1975) Cell 6, 85-100.

6. Lacy, E., and Axel, R. (1975) Proc. Natl. Acad. Sci. USA 72, $3978-3982$.

7. Marmur, J. (1961) J. Mol. Biol. 3, 208-218.

8. Márquez, G., Morán, F., Franco, L., and Montero, F. (1982) Eur. J. Biochem 123, 165-170.

9. Cowman, M.K., and Fasman, G.D. (1980) Biochemistry 19, 532541.

10. Vogt, V.M. (1973) Eur. J. Biochem. 33, 192-200.

11. Britten, R.J., Graham, D.E. and Neufeld, B.R. (1974) Methods Enzymol. 29, 363-418.

12. Stuart, A., and Khorana, H.G. (1964) J. Biol. Chem. 239, 3885-3892.

13. Chambon, P. (1978) Cold Spring Harbor Symp. Quant. Biol. 42, $1209-1234$

14. Weintraub, H., Worcel, A., and Alberts, B. (1976) Cell9, 409-417.

15. Palter, K.B., Foe, V.E., and Alberts, B.M. (1979) Cell 18, $451-467$. 